\title{
Addressing Justified Vaccine Hesitancy in the Black Community
}

\author{
Cato T. Laurencin ${ }^{1,2,3,4,5,6,7}$ \\ Received: 4 February 2021 / Revised: 8 March 2021 / Accepted: 15 March 2021 / Published online: 30 March 2021 \\ (C) W. Montague Cobb-NMA Health Institute 2021
}

\begin{abstract}
The Coronavirus disease 2019 (COVID-19) pandemic has had a terrible and long-lasting impact on the world. As the infection spreads, the projected mortality and economic devastation are unprecedented. Racism and its subsequent effects on social and economic factors have resulted in the virus disproportionally effecting Black people. Given that the virus has hit the Black community the hardest, I am concerned now that vaccine hesitancy may perpetuate the health disparities that we are currently seeing in the numbers of infections and deaths taking place in the Black community.
\end{abstract}

Keywords Vaccine $\cdot$ Vaccine Hesitancy $\cdot$ COVID-19 $\cdot$ Virus $\cdot$ Blacks $\cdot$ Infections

\section{Introduction}

The Coronavirus disease 2019 (COVID-19) pandemic has had a terrible and long-lasting impact on the world. As the infection spreads, the projected mortality and economic devastation are unprecedented.

From the pandemics infancy, my team and I foresaw the challenges this virus would create for Blacks in particular. We published the first peer-reviewed paper on COVID-19 and the Black community entitled "The COVID-19 Pandemic: A Call to Action to Identify and Address Racial and Ethnic Disparities" in the Journal of Racial and Ethnic Health

Cato T. Laurencin

laurencin@uchc.edu

1 Connecticut Convergence Institute for Translation in Regenerative Engineering, University of Connecticut Health Center, 263 Farmington Avenue L7036, Farmington, CT 06030, USA

2 Raymond and Beverly Sackler Center for Biomedical, Biological, Physical and Engineering Sciences, Farmington, CT, USA

3 Department of Orthopaedic Surgery, University of Connecticut Health Center, Farmington, CT, USA

4 Department of Materials Science \& Engineering, University of Connecticut, Storrs, CT, USA

5 Department of Biomedical Engineering, University of Connecticut, Storrs, CT, USA

6 Department of Chemical \& Biomolecular Engineering, University of Connecticut, Storrs, CT, USA

7 African Studies Institute, University of Connecticut, Storrs, CT, USA
Disparities [1]. This paper was the first to provide definitive data showing higher rates of COVID-19-related infections and deaths in Blacks. Our follow-up paper discussed the fact that Blacks are experiencing what I have termed a Pandemic on a Pandemic - COVID-19 and racism [2, 3].

\section{Background}

According to the CDC, as of December 6, 2021, in total, there have been over 20 million cases and over 365,000 deaths from the virus [4]. A further dive into these numbers shows that our initial hypothesis has been unfortunately true; Blacks have suffered tremendously and disproportionately from this virus. The racial and ethnic disparities in the effects of COVID-19 are striking. According to APM Research Lab, Blacks are experiencing COVID-19 death tolls exceeding 1 in 800 nationally, while White Americans are experiencing a death toll at 1 in 3125 nationally [5]. Blacks have COVID-19 death rates of more than 2.7 times White Americans.

Racism and its subsequent effects on social and economic factors have resulted in the virus disproportionally affecting Black people. Our first peer-reviewed paper on COVID-19 stated that Blacks are disproportionately affected by poverty, mass incarceration, infant mortality, limited healthcare access, and health-related conditions including heart disease, diabetes, stroke, kidney disease, respiratory illness, and human immunodeficiency virus (HIV) [1]. We are also more likely to contract the virus and spread it within our communities because we are less likely to be able work from home and 
physically distance ourselves due to living, working, and commuting [6]. Again, all of these factors have historical roots of racism and segregation that have been consciously and unconsciously carried on for decades, and to this day, creating direct and indirect negative effects on Blacks.

Given that the virus has hit the Black community the hardest, I am concerned now that vaccine hesitancy may perpetuate the health disparities that we are currently seeing in the numbers of infections and deaths taking place. Most studies, for instance, at this point, have found that Blacks as a community have the highest levels of individuals who state they will never get the vaccine or are not sure if they will get the vaccine, Fig. $1[7,8]$.

Many studies have noted that Black people cite distrust in the government and in the medical profession. Black people cite our nation's history of racism in medical research and in medical care as key reasons for their hesitancy $[9,10]$. This distrust is totally justified. There are also systemic and structural challenges relating to inadequate vaccine production and distribution; availability of needed vaccination supplies; and geographic, access, and transportation barriers. Recent studies have found that the Black communities are receiving low vaccination rates when compared to their total population. For example, data reported from 35 states by the Kaiser Family Foundation (KFF) showed that the vaccination rates in Whites are two times higher than in Blacks (13\% vs. $7 \%$ ). [11].

\section{Discussion}

What can be done? One thing is to address the lack of Blacks in medicine, and particularly Black men and understand how this lack contributes to mistrust in the healthcare system. In 2018, I served as editor for the National Academies publication entitled "An American Crisis: The Growing Absence of Black Men in Medicine and Science" [12]. The publication addressed how Black men are increasingly underrepresented in the medical profession and how a healthcare workforce with representative numbers of Black men is critical for building trust in the Black community. New studies have suggested that increasing numbers of Black physicians may result in improved quality of care for Black patients, perhaps by addressing conscious and unconscious biases. While Blacks make up $13 \%$ of the US population [13], we comprise only $4 \%$ of US doctors [14], and less than $7 \%$ of medical students $[14,15]$.

In addition, the mass spread of false information on social media can play a large role in decision-making and hesitancy. Access to health information to educate the Black community on vaccines is key. Thus, I am here today to advocate personally for Black people to proceed with the vaccine. I have been a consultant for Johnson and Johnson helping them with work on vaccines. Recently, the Johnson and Johnson vaccine has been made available along with the Pfizer and Moderna Vaccines. Soon, vaccines will be produced by other

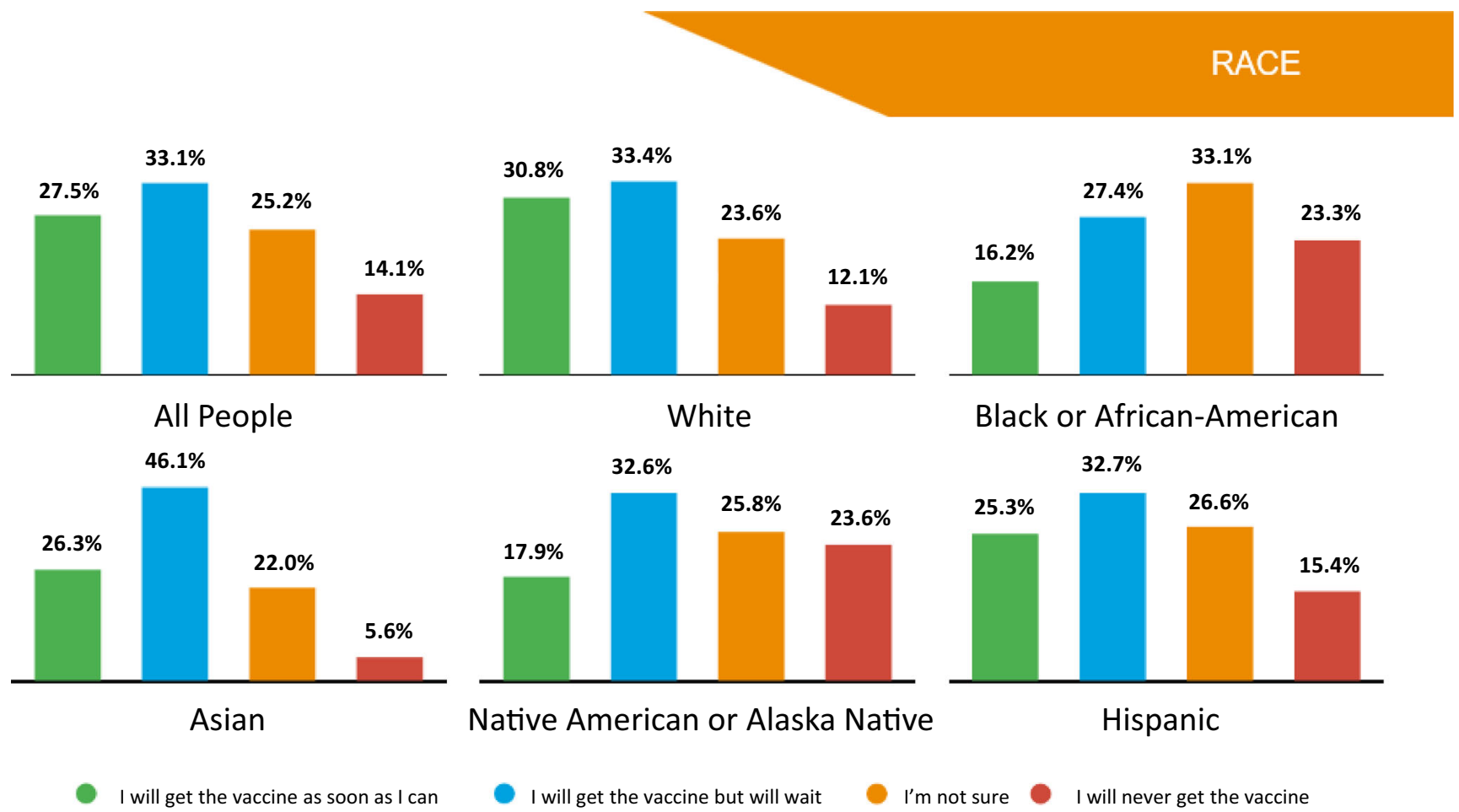

Fig. 1 COVID-19 national vaccinations and data by race [7] 
companies and will be in broad supply. I think we should obtain any vaccine that is available. I have received the Pfizer vaccine.

\section{Future Directions}

Future directions must focus on building trust in the Black community. We must increase the numbers of Black physicians, and increase the number of Black nurses, pharmacists, dentists, and allied health professionals. We also need to focus a great deal of effort on improving vaccine confidence by providing more information to the Black community on the scientific research involved in vaccine development. Medical establishments, including public health agencies, should do more to inform the populations [16]. There is also a major need for clear communication and lay language for communities to understand any health-related information pertaining to the vaccine [17]. Providing vaccine information/ communication geared towards ethnic and minority populations online and in physical locations such as churches, mosques, faith-based institutions, barber shops, hair salons, and other trusted community-based organizations in addressing vaccine hesitancy and providing vaccine and healthrelated information is key for ensuring that information reaches these communities and answers any questions regarding the vaccine $[18,19]$.

\section{Conclusion}

In sum, questions and hesitancy on the part of the Black Community exist. I want to emphasize that they are completely justified. I believe in the balance that the Black Community should proceed in being vaccinated against the COVID-19 virus. I also believe that the medical profession must do more to improve care and create trust in the Black community.

Funding The author received funding for this work from the National Institutes of Health (NIH): NIH BUILD (RL5GM118969) and NIH PIONEER (DP1AR068147) (CTL) as well as support from the Raymond and Beverly Sackler Foundation.

Declarations Dr. Laurencin's Perspective article presents, in large part, his remarks in conjunction with a video presentation describing his experiences in being administered the COVID-19 vaccine.

Ethical Approval This article does not contain any studies with human participants or animals performed by any of the authors.

Informed Consent Not applicable.
Conflict of Interest Dr. Laurencin is a member of the board of MiMedx Company. Dr. Laurencin has served as a consultant for Johnson and Johnson Company.

\section{References}

1. Laurencin CT, McClinton A. The COVID-19 pandemic: a call to action to identify and address racial and ethnic disparities. J Racial Ethn Health Disparities. 2020;7(3):398-402. https://doi.org/10. 1007/s40615-020-00756-0.

2. Laurencin CT, Walker JM. A pandemic on a pandemic: racism and COVID-19 in Blacks. Cell Syst. 2020;11(1):9-10. https://doi.org/ 10.1016/j.cels.2020.07.002.

3. Stein, R.. Troubling history in medical research still fresh for Black Americans. NPR. 2017. https://www.npr.org/sections/health-shots/ 2017/10/25/556673640/scientists-work-to-overcome-legacy-oftuskegee-study-henrietta-lacks.

4. Demographic trends of COVID-19 cases and deaths in the US reported to CDC. Center for Disease Controls. 2021. https:// covid.cdc.gov/covid-data-tracker/\#demographics.

5. COVID-19 deaths analyzed by race and ethnicity. APM Research Lab. 2021. https://www.apmresearchlab.org/covid/deaths-by-race

6. Schmidt H, Gostin LO, Williams MA. Is it lawful and ethical to prioritize racial minorities for COVID-19 vaccines? JAMA. 2020;324(20):2023-4. https://doi.org/10.1001/jama.2020.20571.

7. NRC Health. Updated COVID vaccinations study: have consumers' opinions about the vaccine changed with an upcoming release? 2020. https://nrchealth.com/updated-covid-vaccinationsstudy-have-consumers-opinions-about-the-vaccine-changed-withan-upcoming-release/.

8. Press Ganey Media. Press Ganey COVID-19 vaccine hesitancy research finds Black/African American patients far less willing than Asian or White patients to get the vaccine. Business Wire. 2021. https://www.businesswire.com/news/home/20210204005712/en /Press-Ganey-COVID-19-Vaccine-Hesitancy-Research-FindsBlackAfrican-American-Patients-Far-Less-Willing-Than-Asianor-White-Patients-to-Get-the-Vaccine/?feedref= J j A w J u N H i y s t n C o B q_ h 1 aWOJSq7maz1kU1sOIrkZM4xz5QOdfJiTifxwfmkU5A67fx FuNFTHSunhvli30R1BNXya2izy9YOgH1BiZQk2LPgx NjXHjsNmKaXEz4koEK2KQOELXF1Klv27yoigQe38g==.

9. Malik AA, McFadden SM, Elharake J, Omer SB. Determinants of COVID-19 vaccine acceptance in the US. EClinicalMedicine. 2020;26:100495. https://doi.org/10.1016/j.eclinm.2020.100495.

10. Ellis NCT. Nearly one third of Black Americans remain hesitant to get Covid-19 vaccine, study finds. CNN. 2020. https://edition. cnn.com/2020/12/15/us/black-americans-and-vaccine-hesitancy/ index.html.

11. Ndugga N, Pham O, Hill L, Artiga S, Mengistu S. Latest data on COVID-19 vaccinations race/ethnicity. Kaiser Family Foundation (KFF). 2021. https://www.kff.org/coronavirus-covid-19/issuebrief/latest-data-on-covid-19-vaccinations-race-ethnicity/.

12. Laurencin CT, Murray M. An American crisis: the lack of Black men in medicine. J Racial Ethn Health Disparities. 2017;4(3):31721. https://doi.org/10.1007/s40615-017-0380-y.

13. Vince RA Jr. Eradicating racial injustice in medicine-if not now, when? JAMA. 2020;324:451-2. https://doi.org/10.1001/jama. 2020.12432

14. Gaines P. Black social workers face stress, racial inequities during COVID-19 pandemic. 2020. Retrieved June 4, 2020 from https:// www.nbcnews.com/news/nbcblk/black-social-workers-face-stressracial-inequities-during-covid-19-n1194431.

15. Frakt A. Race and medicine: the harm that comes from mistrust. 2020. Retrieved June 4, 2020 from https://www.nytimes.com/2020/ 
01/13/upshot/race-and-medicine-the-harm-that-comes-frommistrust.html.

16. Warren RC, Forrow L, Hodge DA, Truog RD. Trustworthiness before trust - Covid-19 vaccine trials and the Black community. N Eng1 J Med. 2020;383:e121. https://doi.org/10.1056/ NEJMp2030033nengljmed383;22.

17. Biasio LR, Bonaccorsi G, Lorini C, Pecorelli S. Assessing COVID19 vaccine literacy: a preliminary online survey. Human vaccines \& immunotherapeutics, 1-9. Advance online publication. 2020. https://doi.org/10.1080/21645515.2020.1829315.

18. MacInnis A. Black churches step in to help distribute COVID-19 vaccines. Christianity Today. 2021. https://www.christianitytoday. com/news/2021/january/black-church-covid19-vaccine-floridaprogram.html.

19. Perlow B, Moton K. Barbershops in Black communities provide information on COVID-19, vaccine. ABC News. 2021. https:// abcnews.go.com/Politics/barbershops-black-communities-provideinformation-covid-19-vaccine/story?id=75198074.

Publisher's Note Springer Nature remains neutral with regard to jurisdictional claims in published maps and institutional affiliations. 